\title{
Study of prevalence of dry eye disease in bank employees
}

\author{
Vasudha Damle1,*, Prakash Chand Agarwal², Sanjeev Kumar Gupta ${ }^{3}$ \\ ${ }^{1}$ Assistant Professor, ${ }^{2}$ Professor and HOD, Dept. of Ophthalmology, RKDF Medical College Hospital \& Research Centre, \\ Bhopal, Madhya Pradesh, ${ }^{3}$ Associate Professor, Dept. of Community Medicine, RKDF Medical College Hospital \& Research \\ Centre, Bhopal, Madhya Pradesh, India
}

*Corresponding Author:

Email: vasudhadamle68@gmail.com

\begin{abstract}
Aim: To find out the correlation of working hours on computers and severity of dry eye disease in bank employees. Materials and Methods: Study was done on in total 300 bank employees in the age group of 25 to 45 years. All the cases were divided into 3 groups depending on duration of working hours on monitor, Group A ( 0 hours to $\leq 3$ hours), Group B ( $>3$ hours to $\leq 6$ hours) and Group C (> 6 hours to 9 hours). No statistically significant difference was found gender and age wise amongst 3 groups. In Group A, mean age was $29.35 \pm 5.5$, in Group B it was $30.17 \pm 5.51$ and in Group C it was $30.28 \pm 5.52$ ). On the basis of OSDI Questionnaire, Schirmer's test and tear film break up time (TFBUT), severity of dry eye was assessed.

Results: With OSDI Questionnaire mild to moderate dry eye was found in (GR A $12 \%<$ GR B 79\% <GR C 84\%) and also statistically significant. We noticed cases with mild to moderate dry eye with Schirmer's test (GR A $8 \%<$ GR B $26 \%<$ GR C $38 \%$ ) and with TFBUT (GR A 11\% < GRB 35\% < GR C 47\%) also, though statistically insignificant.

Conclusion: OSDI questionnaire combined with Schirmer's test and TFBUT is a useful tool to assess dry eye disease. OSDI is a very important tool for functional assessment. Simple remedies like position of monitors and frequent blinking can improve the work efficiency.
\end{abstract}

Keywords: Dry eye disease, Schirmer's test, Tear film break up time (TFBUT), Computer vision syndrome \& visual display terminus.

\section{Introduction}

Almost 2-3 decades ago banking job involved lots of manual work like reading, filing, typing and some non sedentary work also. All these activities being different in nature, were associated with change of position and posture. Apart from this, there was limited use of air conditioners. With change in life style and technological advancement, there is more and more use of visual display devices. On one hand it is leading to better quality of work but simultaneously resulting in serious occupational hazard like computer vision syndrome which includes asthenopic problems, vision related problems, neck pain and dry eye..$^{1,2}$

Normal tears are made up of 3 layers. Outer one is lipid layer which prevents evaporation and $90 \%$ of the tear volume is made up of water with a low concentration of salt which constitutes the middle layer. Innermost layer is mucin layer which binds tear film with epithelium. Constant working on monitors leads to quick evaporation from the surface due to inefficient blinking $^{3}$ or change in composition like deficiency of mucin leading to unstable tear film. In Osaka study in Japanese office workers who were working on monitors, they found decreased concentration of a substance called Mucin 5AC in tears. ${ }^{4}$ Position of monitor also plays a major role. Looking straight ahead or up instead of downward gaze reduces blink rate and decrease production of tears which leads to dry eye. Lighting, glare, display quality, refresh rates and radiation also contributes to dry eye.

Various definations have been proposed and International Dry Eye Workshop (DEWS) revised the definition of dry eye in 2007 which is widely accepted. According to the revised definition DED is "a multifactorial disease of the tears and ocular surface that results in symptoms of discomfort, visual disturbance and tear film instability, with potential damage to the ocular surface. It is accompanied by increased osmolarity of the tear film and inflammation of the ocular surface". 5

There are various parameters to assess dry eye disease. Apart from tear film evaluation which includes tear break-up time (TBUT) and Schirmer test, there are different patient reported output questionnaires which can be used subjectively and helps in screening, diagnosis, monitoring and treatment of dry eye. One is FDA PRO guideline and another is OSDI Questinnaire. ${ }^{6-8}$ OSDI questionnaire was first time introduced in 1997 by the outcomes research group.

According to The Odissey European Consensus Group OSDI has poor reproducibility while DEWS report 2007 has accepted it. It can be used easily at work station and it's a reliable tool to do functional assessment.

Protection of cornea is determined by TFBUT and blink rate. The Ocular Protection Index (OPI) demonstrates how the TFBUT and inter-blink interval (IBI) interact to protect the corneal surface. If the amount of time between blinks is longer than TFBUT, an insufficient tear film leaves the corneal epithelial cells unprotected, exacerbating the signs and symptoms of dry eye. ${ }^{9}$ Normal TFBUT is $15-35$ seconds and less than 10 seconds is alarming. 
Another method to measure the volume of tear film which is most likely due to evaporative loss is assessed by Schirmer's test. Less than $10 \mathrm{~mm}$ wetting of strip after 5 min is significant.

\section{Materials and Methods}

In our study we have done examination of 300 bank employees and we have divided them in 3 groups, 100 patients in each group on the basis of working hours on monitor.

Group A $0-\leq 3$ hours

Group B $>3-\leq 6$ hours

Group C $>6$ hours -9 hours

Inclusion Criteria: All the subjects using computer between the age group of 25-45 years.

Exclusion Criteria: Patients of any acute or chronic inflammatory disease, history of surgery or trauma, contact lens users, patients on any local or systemic drugs, menopausal females and ocular surface disorder. Patients using smart phone for more than 2 hours were not included. Protocol was approved by institutional ethics committee.

Written consent was taken from all the patient.

The subjective complaints and symptoms were evaluated with OSDI questionnaire (Ocular Surface Diseases Index). Visual acuity, refraction, Slit-lamp examination, Schirmer test I, TBUT (tear film break up time) and fundus examination was done in all subjects.

Schirmer's test is a non-invasive superficial procedure to measure the total tear secretions. It is performed with $5 \times 35 \mathrm{~mm}$ strip of Whatman-41 filter paper which is inserted into the lower fornix. There are two ways. In Schirmer's I total tear secretion including basal and reflex secretion is measured. If local anaesthetic is used it will measure only basal secretion but from view point of utility as well as overall effectiveness, use of anaesthetic is controversial. ${ }^{10-12}$

In Schirmer's test II measures reflex secretion following nasal stimulation after insertion of strip.

We used Schirmer's I without anaesthesia. The strip is folded $5 \mathrm{~mm}$ from one end and kept in the lower fornix of both eyes at the junction of lateral one-third and medial two-thirds. The patient will be asked to look up and not to blink or close the eyes. After 5 minutes, wetting of the filter paper strip from the bent end will be measured. Depending upon the amount of wetting, severity of dry eye is assessed and it is categorised as follows.

1. $>15 \mathrm{~mm}$ normal

2. $>10 \mathrm{~mm}-\leq 15 \mathrm{~mm}$ borderline (dry eye suspect)

3. $5 \mathrm{~mm}-\leq 10 \mathrm{~mm}$ mild to moderate keratoconjunctivitis sicca

4. $<5 \mathrm{~mm}$ Severe keratoconjunctivitis sicca

Second parameter is Tear film break up time (TFBUT). TFBUT is the time required for the ocular surface to lose cohesive surface wetting after each blink. When TFBUT is less than the blink rate, the ocular surface is left unprotected, and the signs and symptoms of dry eye are exacerbated. ${ }^{13}$ For TFBUT, fluorescein is instilled with a fluorescein strip and after blinking, a break in the tear film is visible as a dark spot under cobalt blue-filtering light. TFBUT is measured three times with a stopwatch and averaged for analysis. It is the time between last blink and appearance of dry spots. Normal TFBUT is $15-35$ seconds. TFBUT less than 10 seconds is considered abnormal. TFBUT can be assessed subjectively also by symptomatic break up time. Depending upon time it was categorised as follows.

1. $>15$ Seconds normal

2. $>10$ Seconds $-\leq 15$ seconds borderline (dry eye suspect)

3. 5 seconds $-\leq 10$ seconds mild to moderate keratoconjunctivitis sicca

4. $\quad<5$ seconds severe keratoconjunctivitis sicca

Ocular Surface Disease Index Questionnaire (OSDI): It's a questionnaire which will include 12 questions related to symptoms, environmental conditions which can cause dry eye \& functional limitations. Each question has 5 likert type response options. 0 (none of the time) to 4 (all of the time). Total OSDI score is calculated by the formula given below. ${ }^{14,15}$

OSDI $=$ Sum of scores $\times 25 /$ total no of questions answered. Scores range from 0 to 100

$0-12$ representing normal,

13- 32 representing mild to moderate DED

$\geq 33$ representing severe DED

Higher scores represent more disability. Scores are matched with the graph with different colour coding. The index demonstrates sensitivity and specificity in distinguishing between normal subjects and patients with dry eye and is a valid and reliable instrument for measuring the severity of dry eye disease.

Comparative analysis will be done using OSDI questionnaire, Schirmer's test I and TFBUT in different groups and we will work out if there is any correlation between duration of working hours and dry eye disease.

\section{Statistical Analysis}

In present study comparative groups matching was done and all data were entered in excel sheet. Statistical analysis was done by using statistical software SPSS version 20, test of significance applied whenever applicable. $P$ value $<0.05$ considered to be significant

\section{Results}

A total of 100 cases in Group A (using computers 0 - $\leq 3$ hours) age group $25-45$ years (mean age29.35 \pm 5.5 ), 100 cases in Group B (computer use >3 hours $-\leq$ 6 hours) age group $25-45$ years (mean age 30.17 \pm 5.51 ) and 100 cases in Group C (computer use > 6 - 9 hours) age group 25-45 (mean age30.28 \pm 5.52 ) were investigated. There were total 157 males and 143 females and no statistically significant difference found 
age wise or on gender basis amongst 3 groups. Details mentioned in demographic profile. (Table 1)

With Schirmer's test I we got more number of cases with mild to moderate and severe dry eye in Group C in comparison to Group B \& A. Severe dry eye was diagnosed in (GR A 3\%<GR B $8 \%<$ GR C $11 \%$ ), mild to moderate dry eye was seen in (GR A 8\% < GR B 26\% < GR C 38\%) borderline cases were (GR A $18 \%<$ GR B $44 \%>$ GR C $42 \%$ ) and normal cases were (GR A $71 \%>$ GR B $22 \%>$ GR C 9\%). (Table 2 and Fig. 1)

With TFBUT we found almost similar trend and again not statistically significant. Severe dry eye case were (GR A 3\% < GR B5\% < GR C 8\%), in mild to moderate category (GR A $11 \%<$ GR B 35\% < GR C $47 \%$, in borderline category (GR A $14 \%<$ GR B $40 \%>$ GR C $37 \%$ ) and in category of normal BUT (GR A $72 \%>$ GR B $20 \%>$ GR C 8\%) cases were seen. (Table 3 and Fig. 2)

Results of OSDI questionnaire were statistically significant. Severe dry eye cases were (GR A 5\% < GRB $10 \%<$ Group C 14\%) and in mild to moderate category (GR A 12\% < GRB 79\% < GR C 84\%) cases were seen. Normal OSDI was seen in (GR A $83 \%>$ GRB $11 \%>$ Group C 2\%) cases. (Table 4 and Fig. 3)

Table 1: Demographic profile

\begin{tabular}{|c|c|c|c|c|}
\hline & No of patients & $\begin{array}{c}\text { Group A } \\
\text { computer use } \\
0-\leq 3 \text { Hours }\end{array}$ & $\begin{array}{c}\text { Group B } \\
\text { Computer use } \\
>3-\leq 6 \text { hours }\end{array}$ & $\begin{array}{c}\text { Group C } \\
\text { Computer use } \\
>6-9 \text { hours }\end{array}$ \\
\hline \multicolumn{5}{|l|}{ Age group } \\
\hline $25-35$ & 160 cases & 55 cases & 53 cases & 52 cases \\
\hline $36-45$ & 140 cases & 45 cases & 47 cases & 48 cases \\
\hline Total cases & 300 cases & 100 cases & 100 cases & 100 cases \\
\hline Mean age & $\begin{array}{c}30.133 \\
\text { Standard Deviation } \\
\pm 5.49 \\
\text { Variance }=30.216\end{array}$ & $\begin{array}{c}29.95 \\
\text { Standard } \\
\text { Deviation }= \pm 5.5 \\
\text { Variance }=30.25\end{array}$ & $\begin{array}{c}30.17 \\
\text { Standard } \\
\text { Deviation }= \pm 5.518 \\
\text { Variance }=30.446\end{array}$ & $\begin{array}{c}30.28 \\
\text { Standard } \\
\text { Deviation }= \pm 5.523 \\
\text { Variance }=30.507\end{array}$ \\
\hline \multicolumn{5}{|l|}{ Sex } \\
\hline Males & 157 & 51 & 52 & 54 \\
\hline Females & 143 & 49 & 48 & 46 \\
\hline & & Chi-square $=0.187$ & $\begin{array}{l}\text { Degree of freedom } \\
=3 \\
\text { Probability } 0.980\end{array}$ & $\begin{array}{c}\text { No sex wise } \\
\text { difference amongst } \\
3 \text { groups }\end{array}$ \\
\hline
\end{tabular}

Table 2: Interpretation of schirmer's test

\begin{tabular}{|c|c|c|c|c|}
\hline & $\begin{array}{l}<5 \mathrm{~mm} \\
\text { (severe) }\end{array}$ & $\begin{array}{c}5-\leq 10 \mathrm{~mm} \\
\text { (mild to moderate) }\end{array}$ & $\begin{array}{c}>10 \mathrm{~mm}-\leq 15 \mathrm{~mm} \\
\text { Borderline }\end{array}$ & $\begin{array}{c}>15 \mathrm{~mm} \\
\text { (normal) }\end{array}$ \\
\hline \multicolumn{5}{|l|}{ Group A } \\
\hline $\mathrm{RE}$ & $4 \%$ cases & $07 \%$ cases & $17 \%$ cases & $72 \%$ cases \\
\hline $\mathrm{LE}$ & $2 \%$ cases & $09 \%$ cases & $19 \%$ cases & $70 \%$ cases \\
\hline Average & $3 \%$ cases & $8 \%$ cases & $18 \%$ cases & $71 \%$ cases \\
\hline \multicolumn{5}{|l|}{ Group B } \\
\hline $\mathrm{RE}$ & $7 \%$ cases & $25 \%$ cases & $45 \%$ cases & $23 \%$ cases \\
\hline LE & $9 \%$ cases & $27 \%$ cases & $43 \%$ cases & $21 \%$ cases \\
\hline Average & $08 \%$ cases & $26 \%$ cases & $44 \%$ cases & $22 \%$ cases \\
\hline \multicolumn{5}{|l|}{ Group C } \\
\hline $\mathrm{RE}$ & $11 \%$ cases & $37 \%$ cases & $43 \%$ cases & $9 \%$ cases \\
\hline $\mathrm{LE}$ & $11 \%$ cases & $39 \%$ cases & $41 \%$ cases & $9 \%$ cases \\
\hline Average & $11 \%$ cases & $38 \%$ cases & $42 \%$ & $9 \%$ cases \\
\hline
\end{tabular}

Table 3 Interpretation of tear film break up time

\begin{tabular}{|l|c|c|c|c|}
\hline & $<\mathbf{5}$ Sec(severe) & $\begin{array}{c}\mathbf{5} \text { sec }-\leq \mathbf{1 0 s e c} \\
\text { (mild to moderate) }\end{array}$ & $\begin{array}{c}>\mathbf{1 0} \text { sec- } \leq \mathbf{1 5} \text { sec } \\
\text { borderline }\end{array}$ & $\begin{array}{c}>15 \text { sec } \\
\text { normal }\end{array}$ \\
\hline Group A & & & & $73 \%$ cases \\
\hline RE & $4 \%$ cases & $10 \%$ cases & $13 \%$ cases & $71 \%$ cases \\
\hline LE & $2 \%$ cases & $12 \%$ cases & $15 \%$ cases & $\mathbf{7 2 \%}$ cases \\
\hline Average & $\mathbf{3 \%}$ cases & $\mathbf{1 1 \%}$ cases & $\mathbf{1 4 \%}$ cases & \\
\hline Group B & & & & \\
\hline
\end{tabular}




\begin{tabular}{|l|c|c|c|c|}
\hline RE & $6 \%$ cases & $36 \%$ cases & $39 \%$ cases & $19 \%$ cases \\
\hline LE & $4 \%$ cases & $34 \%$ cases & $41 \%$ cases & $21 \%$ cases \\
\hline Average & $\mathbf{5 \%}$ cases & $\mathbf{3 5 \%}$ cases & $\mathbf{4 0 \%}$ cases & $\mathbf{2 0 \%}$ cases \\
\hline Group C & & & & \\
\hline RE & $7 \%$ cases & $46 \%$ cases & $38 \%$ cases & $9 \%$ cases \\
\hline LE & $9 \%$ cases & $48 \%$ cases & $36 \%$ cases & $7 \%$ cases \\
\hline Average & $\mathbf{8 \%}$ cases & $\mathbf{4 7 \%}$ cases & $\mathbf{3 7 \%}$ cases & $\mathbf{8 \%}$ cases \\
\hline
\end{tabular}

Table 4: OSDI Scores

\begin{tabular}{|c|c|c|c|}
\hline & $\begin{array}{c}\text { OSDI score (0-12) } \\
\text { (normal) }\end{array}$ & $\begin{array}{c}\text { OSDI score (13-32) } \\
\text { Mild to moderate DED }\end{array}$ & $\begin{array}{c}\text { OSDI score }(\geq 33) \\
\text { Severe DED }\end{array}$ \\
\hline $\begin{array}{l}\text { Group } A \\
(100 \text { cases })\end{array}$ & $83 \%$ cases & $12 \%$ cases & $5 \%$ cases \\
\hline Group B (100 cases) & $11 \%$ cases & $79 \%$ cases & $10 \%$ cases \\
\hline $\begin{array}{l}\text { Group C } \\
\text { (100 cases) }\end{array}$ & $2 \%$ cases & $84 \%$ cases & $14 \%$ cases \\
\hline
\end{tabular}

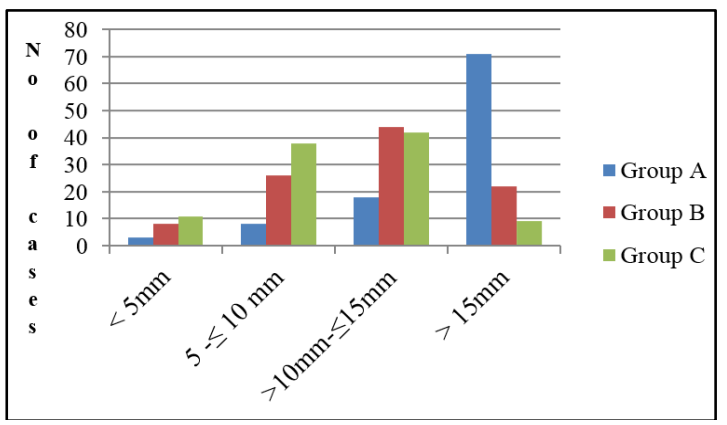

Fig. 1: Interpretation of Schirmer's test

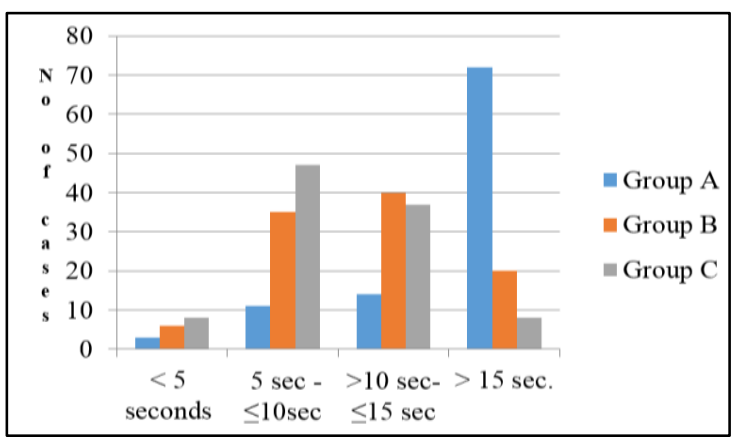

Fig. 2: Interpretation of tear film break up time

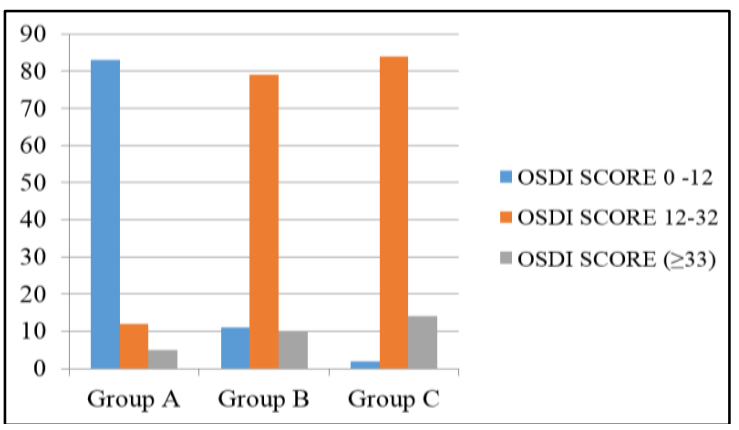

Fig. 3: OSDI scores

\section{Discussion}

Prevalence of dry eye disease varies from country to country and ranges between 5\% to $35 \%$ in different age groups. ${ }^{16-19}$ Approximately 25-30 million people are affected. The prevalence of DED in India is higher than the global prevalence and ranges from $18.5 \%$ to $54.3 \% .^{20,21}$ There is role of various factors which enhance dry eye disease like contact lens users, rheumatoid arthritis, parkinson's disease, female patients and age of the subjects. In females it is higher than males particularly in menopausal age due to imbalance between oestrogen and androgen hormones leading to inflammation of lacrimal gland. ${ }^{22}$ With advancing age, it's not only deficient secretion by lacrimal glands, probably they have used monitors for more number of years. We have not included all these patients in our study as we wanted to know the effect of visual display screens exclusively.

We used OSDI Questionnaire. It helps in early detection. With objective methods, there is poor reproducibility while subjective test assess the quality of life in a better manner. In a study by Titiyal et.al, based on OSDI questionnaire prevalence of dry eye was reported $32 \% .{ }^{23}$ In our study also found significant results with OSDI Questionnaire. In Group C we found severe dry eye in $14 \%$ cases while $10 \%$ and $5 \%$ respectively in Group B and Group A. Though exact correlation between objective and subjective tests was not found but results were not contradictory also.

Protection of cornea is determined by correlation between TFBUT and interblink interval and is known as Ocular Protection Index (OPI). If BUT time is lesser than blink rate, cornea is unprotected. Mean blink rate is 22 per min in relaxed state and according to some of the studies it's 10 per min when reading a book and 7 per min on the computers. ${ }^{24,25}$ So probably it is the decreased blink rate which causes more evaporation of tears.

Apart from measurement of TFBUT by objective method using fluorscein dye, it can be assessed subjectively also by Symptomatic break up time. It is usually 1 min delayed than TFBUT. 


\section{Conclusion}

With change of life style and inadvertent use of technology, most of the manual work in the banks is done on monitors. Higher stress level, use of air conditioners, improper position of monitors and constant staring is associated with poor blinking and so the associated symptoms of dry eye. This has affected overall work efficiency and so the output of organisation.

This type of studies helps in finding actual correlation of dry eye with use of computers and assessing the relation of severity of dry eye with duration of computer use. Patients' education, deliberate ergonomics of computer use, including screen height, blinking exercises, chair position, glare protection and artificial tear substitutes used in order to minimize the symptoms of dry eye syndrome and prevent serious complications. OSDI score is a very informative tool for functional assessment.

Breaks and Blinking: Avoid eyestrain by preventing continuous use of eyes by taking short breaks. One of the golden rule is ' $20-20-20$ ' rule, every 20 minutes, focus the eye on an object 20 feet ( 6 meters) away for 20 seconds OR blink every time you hit the "ENTER" key or mouse click.

Lowering the monitor by 10 to 20 degree from eye level can reduce the palpebral aperture and so reduces evaporation of tears.

Acknowledgement: I am highly thankful to the department of Ophthalmology RKDF medical college, my family members for their moral support and all the bank employees for their valuable support.

\section{References}

1. Hagan S, Lory B. Prevalence of dry eye among computer users. Optom Vis Sci. 1998;75:7123.

2. Patil SD, Trivedi HR, Parekh NV, Jethva JJ. Evaluation of dry eye in computer users. Int J Community Med Public Health 2016;3:3403-7.

3. Koslowe KC, Hadas W, Biner-Kaplan M. The Blink Frequency Relationship between Reading from a Computer Screen and Reading from a Printed Page. Optometry and Vision Development 2011;42:168. Rinalducci EJ. Video displays, work, and vision. Chairman, Committee on Vision, National Research Council. Washington DC: National Academy Press; 1983.

4. Uchino $\mathrm{Y}^{1}$, Uchino $\mathrm{M}^{2}$, Yokoi $\mathrm{N}^{3}$, Dogru $\mathrm{M}^{1}$, Kawashima $\mathrm{M}^{1}$, Okada $\mathrm{N}^{1}$, Inaba $\mathrm{T}^{4}$, Tamaki $\mathrm{S}^{4}$, Komuro

$\mathrm{A}^{3}$, Sonomura $\mathrm{Y}^{3}$, Kato $\mathrm{H}^{3}$, Argüeso $\mathrm{P}^{5}$, Kinoshita $\mathrm{S}^{3}$, Tsubota $\mathrm{K}^{1}$. Alteration of tear mucin $5 \mathrm{AC}$ in office workers using visual display terminals: The Osaka Study. JAMA Ophthalmol, 2014 Aug;132(8):985-92. doi:10. 1001 /jamaophthalmol.2014.1008.

5. 2007 Report of the International Dry Eye Workshop (DEWS). The Ocular Surface. 2007;5:65-204.

6. Schiffman RM, Christianson MD, Jacobsen G, Hirsch JD, Reis BL. Reliability and validity of the ocular surface disease index. Arch Ophthalmol 2000;118:615-21.

7. Guillemin I, Begley C, Chalmers R, Baudouin C, Arnould B. Appraisal of patient-reported outcome instruments available for randomized clinical trials in dry eye: Revisiting the standards. Ocul Surf 2012;10:84-99.

8. Grubbs JR Jr., Tolleson-Rinehart S, Huynh K, Davis RM. A review of quality of life measures in dry eye questionnaires. Cornea 2014;33:215.

9. Ousler GW 3rd ${ }^{1}$, Hagberg KW, Schindelar M, Welch $\mathrm{D}$, Abelson MB The Ocular Protection Index. Cornea. 2008 Jun;27(5):509-13. doi10.1097/ICO.0b013e31816583f6.

10. Clinch TE, Benedetto DA, Felberg NT, et al. Schirmer's test. Acloser look. Arch Ophthalmol. 1983;101:1383-6.

11. Afonso AA, Monroy D, Stern ME, et al. Correlation of tear clearance and Schirmer test scores with ocular irritation symptoms. Ophthalmol. 1999;106:803-10.

12. Michelle Senchyna \& Martin B Wax. Quantitative assessment of tear production: A review of methods and utility in dry eye drug discovery. J ocul biol dis inform (2008) 1:1-6 DOI 10.1007/s12177-008-9006-2.

13. Lemp MA, Hamill JR Jr. Factors affecting tear film breakup in normal eyes. Arch Ophthalmol 1973;89:103-5.

14. Walt JG, Rowe MM, Stern KL. Evaluating the functional impact of dry eye: The ocular surface disease index. Drug Inf $J$ 1997;31:1436.

15. Grubbs JR Jr., Tolleson-Rinehart S, Huynh K, Davis RM. A review of quality of life measures in dry eye questionnaires. Cornea 2014;33:215-8.

16. Ranjan R, Shukla S, Singh C, Mishra B, Sinha S, Sharma B. Prevalence of Dry Eye and Its Association with Various Risk Factors in Rural Setup of Western Uttar Pradesh in a Tertiary Care Hospital. Open J Preventive Medicine. 2016;6:57-63.

17. The epidemiology of dry eye disease: Report of the Epidemiology. Subcommittee of the International Dry Eye Workshop (2007). OculSurf 2007;5:93-107.

18. McCarty CA, Bansal AK, Livingston PM, Stanislavsky YL,Taylor HR. The epidemiology of dry eye in Melbourne, Australia. Ophthalmology 1998;105:1114-9.

19. Lin PY, Tsai SY, Cheng CY, Liu JH, Chou P, Hsu WM, et al. Prevalence of dry eye among an elderly Chinese population in Taiwan: The Shihpai eye study. Ophthalmology 2003;110:1096-101.

20. Gupta N, Prasad I, Jain R, D'Souza P. Estimating the prevalence of dry eye among Indian patients attending a tertiary ophthalmology clinic. Ann Trop Med Parasitol 2010;104:247-55.

21. Shah S, Jani H. Prevalence and associated factors of dry eye: Our experience in patients above 40 years of age at a tertiary care center. Oman J Ophthalmol 2015;8:151-6.

22. Michael 0 et.al, Treatment of menopausal keratoconjunctivitis sicca with topical oestradiol. British Journal of Obstetrics and Gynaecology January 1998, Vol. 105, pp. 100-102.

23. Titiyal JS, Falera RC, Kaur M, Sharma V, Sharma N. Prevalence and risk factors of dry eye disease in North India: Ocular surface disease index-based cross-sectional hospital study. Indian J Ophthalmol 2018;66:207-11.

24. Tsubota K, Nakamori K. Dry eyes and VDTs. N Engl J Med. 1993;328:584-5.

25. Bentivoglio $\mathrm{AR}^{1}$, Bressman SB, Cassetta E, Carretta $\mathrm{D}$, Tonali $\mathrm{P}$, Albanese Analysis of blink rate patterns in normal subjects. A Mov Disord. 1997 Nov;12(6):102834. 